\title{
Festas nacionais: uso e didatização do saber histórico nas pedagogias do cidadão
}

Luis Fernando Cerri *

RESUMO

\begin{abstract}
Se a História ensinada é a "pedagogia central do cidadão", é preciso reconhecer que seu trabalho pedagógico não ocorre apenas no ambiente escolar. A presente pesquisa procurou identificar o "currículo oculto" das festas nacionais do Descobrimento do Brasil, em 1900 e em 2000, identificando os conhecimentos históricos utilizados e suas relações com os respectivos contextos. 0 levantamento de informações foi feito através da análise de documentos escritos, sobretudo da imprensa. Verificou-se que as temáticas da festa nacional foram similares em cada momento, embora 0 tratamento seja totalmente distinto: a periodização da história, a definição dos sujeitos históricos e dos sujeitos da comemoração, a significação dos monumentos, entre outros.
\end{abstract}

Palavras-chaves: ensino de história, saber escolar, currículo, festas nacionais

\section{Escavando os alicerces do monumento}

Na festa cívica ocorre o ensino da História? Para responder a essa questão é preciso antes definir o que é esse fenômeno social, o ensino da História. Uma visão estrita 0 entende como a relação educativa que envolve professor e aluno na sala de aula da escola formal. Esta visão pode ser um pouco dilatada se considerarmos que a História também pode ser ensinada em programas de menor grau de formalidade, como o ensino a distância e as situações educativas distintas da escola: cursos de profissionalização, de formação sindical ou partidária, dentro dos movimentos sociais... Mas se formos ainda um pouco além, e considerarmos que o ensino da História envolve qualquer situação em que um sujeito consegue transmitir a outro determinada idéia, informação, valor, referente ao passado ou ao tempo como um todo, poderemos vislumbrar o

\footnotetext{
* Professor de prática de ensino do Departamento de História da Universidade Estadual de Ponta Grossa-PR .E-mail: lfcerri@uepg.br.
} 
ensino da história ocorrendo nos mais diversos espaços. Como se enterrassem minas, pessoas e grupos dotados de algum poder nominam ruas, erigem monumentos, plantam estátuas, promovem rituais imprevistos ou praticam rituais cíclicos, comemoram aniversários de datas da coletividade. Essas minas de memória, ou saber histórico, ou memória histórica, são detonadas diante de qualquer olhar menos distraído que resolve perguntar por quêe, mas também infiltram sua pólvora nos distraídos, numa espécie de ação subconsciente que gera posturas irrefletidas como a familiaridade, a plausibilidade e um certo conservadorismo quanto ao universo em que se vive, de modo que qualquer mudança expressiva choca, desagrada e estranha sem que isso passe pelos caminhos da razão. Andando por essas veredas muito antes de chegar à escola, o aluno irá receber suas lições de história não como algo absolutamente novo (como a imprevista existência da análise morfológica ou dos teoremas sobre os ângulos nas figuras geométricas), mas como algo sobre o que já se traz algumà coisa, nem que seja apenas uma impressão.

Ao aceitar a idéia de que, mais que um ensino de História (termo que tende a uma unilinearidade de mensagens do professor-sujeito ao aluno-objeto), nosso objeto cresce para uma educação histórica que se estende por toda a vida, deve-se reconhecer também que o que se ensina ou vai predominar em termos de conhecimento aceito socialmente é objeto de violentos combates entre grupos distintos, já que isso define grande parte do que se faz na coletividade. Por exemplo, a compreensão coletiva do que foi a escravidão, quais suas conseqüências e quem deve assumir as responsabilidades, pode gerar uma série de aceitações ou recusas quanto a temas de interesse coletivo, como reparações financeiras a serem pagas pelo Estado, a atribuição do título de propriedade a remanescentes de quilombos, as quotas para negros nas vagas das Universidades ou do serviço público.

Se tomarmos como ponto de partida que no surgimento do Brasil como unidade política autônoma, o Estado atua na constituição da nação, deveremos reconhecer que, para além da circulação social de conceitos e conhecimentos históricos, o ensino oficial assume um papel fundante. Numa consagrada frase, a História ensinada galgou a condição de pedagogia central do cidadão, surgida no objetivo de formar "o cidadão compenetrado de seus deveres e um soldado que ama a sua arma” (FURET, s.d., p. 130). Presente desde o império, é com a laicização da República que o ensino de História começa a ganhar impulso para o cumprimento desta função nacionalizadora, civilizadora e europeizante 
(NADAI, 1988 e 1992/93). Mas além da aula de História, a nacionalidade e os conteúdos necessários ganham espaços de emissão diferenciados, como as outras disciplinas escolares (os textos de Língua Pátria e os hinos do Canto Orfeônico, por exemplo) e atividades extracurriculares como os desfiles e as festas cívicas, que transbordam a escola. 0 enquadramento das mesmas como objeto da pesquisa do ensino de História não é novidade, estando presente em artigos como As ' tradições nacionais' e o ritual das festas cívicas, de Circe M. F. Bittencourt (1988).

Para Bergmann, de acordo com Jeissmann, a Didática da História é a disciplina, afeta ao estudo científico da História, "indaga sobre o caráter efetivo, possível e necessário de processos de ensino e aprendizagem e de processos formativos da História. Nesse sentido (...) se preocupa com a formação, o conteúdo e os efeitos da consciência histórica" (Bergmann, 1989/90, p. 29). Para esse autor, o dado comum a todo ensino de História é a existência de uma (ou mais que uma) identidade a formar, o que torna a tarefa de investigar o que se pensa, o que se aprende e o que se ensina sobre a História e a memória dos grupos no tempo, uma tarefa imprescindível dessa disciplina. As festas cívicas são um expoente importante, um momento de concentração e síntese desses enunciados, sejam eles estáveis ou submetidos à crise dos diversos sujeitos e seus pontos de vista.

Identificamos nas festas referentes ao Descobrimento no século XIX (1900) e no século XX (2000), oportunidades ímpares para o estudo desse ensino de História que permeia o tecido social e alinhava-o com fios de identidade nacional, as características de sua urdidura e os sobressaltos que fazem com que as configurações finais não sejam aquelas planejadas pelos tecelões. As comemorações do descobrimento envolvem um elemento fundamental da memória histórica ${ }^{1}$, que é compartilhamento coletivo do mito de origem da

1 De DECCA refere-se, no artigo "Memória e cidadania", a uma tendência, na modernidade, de estabelecimento de memória histórica, ocupando o espaço da memória. Aquela se caracterizaria, ao contrário desta, por não ser espontânea e por não estar necessariamente vinculada à experiência vivida: trata-se de ensinar ao sujeito lembranças que não vivenciou, mas que julga-se serem de suma importância para o resgate ou a conservação da sua identidade. A memória histórica, para De Decca, caracteriza-se também pela ausência de sentido crítico, de análise do passado e de busca da diferença. A memória histórica encontra no passado apenas o que a confirma no presente, fugindo da negação, da contradição, da diferença, porque o seu sentido é harmonizar e unificar, é identificar. É neste sentido que o ensino de história - na escola ou fora dela - é mobilizado pelo Estado moderno para formar o cidadão que se integra à pátria. Portanto, não é exagero afirmar que o ensino de história tal como se estabeleceu historicamente ao longo do século XIX, mais que um ensino propriamente da história (entendida como saber laico, exercício da crítica, questionamento da memória) é um exercício de memória histórica a ser assumido por uma nação como uma das formas principais de identificar-se. 
nação, entendido em suas acepções narrativas, antropológicas e psicanalíticas: "impulso à repetição de algo imaginário, que cria um bloqueio à percepção da realidade e impede lidar com ela." (CHAUÍ, 2000, p. 9). A festa do Descobrimento é mobilizadora de comemorações e debates nos quais o tema central é a identidade nacional, não apenas em um dos seus vértices constitutivos, mas em sua totalidade. 0 conteúdo do Descobrimento é também fundador no ensino da História: até anedoticamente, a pergunta básica do saber histórico escolarizado é quem descobriu o Brasil?. Reveladora de uma leitura personalista do desenvolvimento histórico, a pergunta remete também a uma negritagem das origens, como marca de início da coletividade nacional: o que as fronteiras políticas e naturais realizam em termos imaginários, ao constituir a certeza da nação em nós, as datas fazem para o tempo pelo qual temos (ou teríamos) existido como coletividade.

Para Mona Ozouf, a festa cívica é um rico momento ritualístico que permite um retrato, tanto dos discursos que pretendem dar forma e unidade ao coletivo nacional, quanto, aguçando o olhar, perceber as fragilidades e os conflitos internos e inerentes a essa pretensa unidade. Acima disso, entretanto, comemorar é ter a capacidade de anular, ou no mínimo de suspender indefinidamente os conflitos, e proclamar a ipseidade:

Toda comemoração vive da afirmação obsessiva do mesmo. Os programas das festas, os planos para os cortejos, os projetos de monumentos e os discursos martelam quatro afirmações pelo menos: de que nos honramos de ser os mesmos (entre eles), nós somos todos os mesmos (entre nós), nós somos sempre os mesmos que antes, nós permaneceremos os mesmos. Não há comemoração sem este conjunto, sem este permanente conjunto. (OZOUF, 1984, p. 143)

É também oportuna a citação de Chesneau sobre essa temática:

Todos esses aniversários e comemorações (...) funcionam exatamente da mesma forma: patrocínio oficial, estatal, de uma celebração histórica, espetáculo de massa com divertimentos populares; esquematização de um evento passado como suporte da ideologia dominante; ocultação dos aspectos não - oficiais do acontecimento escolhido, notadamente, das provações e lutas dos setores populares. (CHESNEAU, 1995, p. 31) 
Diante do imbróglio de comemorar a Revolução Francesa, os membros das comissões organizadoras vão reconhecendo, entretanto, a impossibilidade de manter esse discurso da ipseidade: contrariamente à sua vontade comemorativa, eles não são mais todos os mesmos, apesar do forte desejo de identificação. Dentro do mesmo campo da comemoração, as pessoas se dividem, como no centenário, em que se formaram duas associações republicanas concorrentes, uma oportunista e uma radical; em 1939, no sesquicentenário, haviam dois grupos operários disputando a herança revolucionária. Força-se ainda uma outra descoberta: quaisquer que sejam os celebrantes, eles não são mais os mesmos que antes, eles mudam à medida em que passam os anos de preparação para 0 aniversário, mesmo na conjuntura menos agitada do centenário. Nos diferentes anos jubilares da Revolução, 1889, 1939, 1989, Ozouf indica que o objeto comemorado não é homogêneo, e que a revolução francesa não é uma evidência, mas um problema: qual lado da revolução comemorar, nos seus 10 anos que incluem também o Terror, a guilhotina, o confronto traumático de grandes figuras antagônicas, como Danton e Robespierre? (OZOUF, p. 148) Essa discussão conduz a uma decisão radical: para comemorar, é necessário suprimir aquilo que destrói a memória histórica, enquanto trabalho identitário e identificador dos comemorantes no presente. Isso leva a uma periodização lacunar das comemorações, truncada pela guilhotina, que corta o corpo da festa em duas partes: 0 comemorável e 0 incomemorável.

Com as devidas proporções e especificidades guardadas, a comemoração do Descobrimento é aparentemente menos problemático para os brasileiros que a Revolução para os franceses, entretanto a incomemorabilidade é um fantasma que também nos ronda: um mito de origem não traz referências apenas ao seu tempo, mas a todo o tempo daquilo que funda. Se o encontro de Cabral com os indígenas foi pacífico e mesmo jovial, a História que se seguiu não pode afirmar o mesmo sem esburacar a narrativa de lacunas.

\section{Brasil 400, Brasil 500}

Em 1900, a comemoração tem um caráter muito mais restrito que em 2000, pela ausência de uma efetiva integração nacional, que só teve espaço no longo processo que vai da generalização do uso do rádio (década de 30) até a 
viabilidade de um sistema nacional de telecomunicações (década de 1970). Embora acompanhada pela imprensa e impulsionada a partir de uma comissão heterogênea, trata-se sobretudo de um festim oficial, cerimonioso, restrito aos centros urbanos. Em 2000, a festa chega aos mais isolados rincões no lombo das ondas de televisão. $\mathrm{E}$ apesar das muitas outras diferenças que poderemos levantar, trata-se de uma abordagem comparativa promissora, porque em dois momentos separados entre si por um século, dois Brasis absolutamente distintos dobram-se sobre o seu tempo e indagam ao presente a vontade de continuar sendo os mesmos, já que o passado usado nas festas afirma essa ipseidade. Entretanto, cada uma a seu modo, nenhuma das festas passa completamente ao largo da sombra da incomemorabilidade.

Tradicionalmente, o método comparativo pressupõe sociedades distintas tomadas sincronicamente. É o caso do belíssimo livro Multidões em cena, de Maria Helena Capelato, em que o populismo varguista e o populismo peronista, em termos de suas linguagens e efeitos sobre a cultura política de Brasil e Argentina, são postos em discussão. Embora evocando as propostas de Marc Bloch para o método comparativo no trabalho com a história das sociedades européias, e reconhecendo o lugar ainda secundário ocupado por essa metodologia, Haupt (1998) aponta esta mesma perspectiva dos estudos sincrônicos, restando a comparar os espaços diferentes em que processos parecidos ocorreram. Sem grandes pretensões, a perspectiva de nossa pesquisa foi, ao contrário, tomar um encaminhamento diacrônico: os pólos de comparação não são espaços distintos, mas teoricamente um mesmo espaço, o território brasileiro, em dois momentos distintos.

Essa comparação permite pôr em evidência a historicidade dos consensos sobre os quais se edificam os conhecimentos e os discursos sobre a história que serão autorizadamente utilizados, permite vislumbrar como os contextos afetam diferentemente esses consensos, como os dissensos sobrevivem e se alteram. Com isso, pretende-se adicionar dados à tese de que o conhecimento histórico, quando usado para as funções sociais de criação, fortalecimento ou redirecionamento de identidades coletivas, consegue com relativa facilidade lograr as regras de procedimento da ciência da História, sem perder a carga de confiabilidade que ela oferece, compondo a miscelânea da memória histórica, em que elementos oriundos da pesquisa mesclam-se com interesses 
identificadores e afetivos em relação ao passado, isolando a contaminação dos traumas pretéritos e fornecendo o material, no campo das idéias, para os enunciados comemorativos.

\section{A maquinação das datas}

A data, na narrativa histórica, estabelece o período: funciona como 0 marco de fronteira, para a definição do território. Tanto a representação visual do território da nação (ROBIC, 1989) quanto a definição do tempo de sua existência, são símbolos de massa e / ou lugares de memória, pelos quais passa a identificação entre 0 indivíduo e a coletividade. Guerras são travadas pela definição das fronteiras; no campo simbólico, outras guerras também são travadas pelo balizamento temporal, pela definição dos períodos.

A primeira dessas batalhas a olhar é a definição do dia da comemoração do Descobrimento, em 1900. A festa é oficialmente estabelecida para o dia 3 de Maio, embora o 22 de Abril permaneça como ponto de interrogação, por ser a data citada na Carta de Pero Vaz de Caminha ${ }^{2}$. Essa batalha é pouco violenta, pois trata-se de uma definição menor, dentro de uma mesma posição estratégica, como se definíssemos, no nosso time, se é Fulano ou Beltrano quem dá o pontapé inicial. 03 de maio é uma baliza da monarquia, primeiramente atribuída ao Descobrimento; a República o oficializa explicitamente como a data da descoberta de Cabral, consagrando o costume que é mesmo anterior ao império, e apesar da descoberta (!) da Carta de Caminha em 1817. A explicação da época ${ }^{3}$ varia em torno da mudança do calendário cristão em 1582, da idéia de que 03 de Maio celebra a posse, e não 0 avistamento da nova terra (o que encaixa bem com a perspectiva oficialista e diplomática da historiografia de então), ou da idéia pura e simples da tradição, ou seja, que comemorava-se 03 de Maio porque assim havia sido desde a Colônia, com 0 testemunho de diversos cronistas daquele período.

\footnotetext{
2 Apesar disso, o Instituto Histórico e Geográfico do Brasil promove sua sessão solene, com a presença do presidente da República, Campos Sales, em 22 de Abril de 1900 (0 Paiz, 23 de Abril de 1900, p. 1).

3 Referimo-nos ao texto "A Chronologia e a história pátria", de João Lourenço Rodrigues, publicado no Almanak de Piracicaba para o anno de 1900, pp. 421-5.
} 
03 de Maio oferece à festa de 1900, portanto, o peso da tradição. Para a jovem República, com frustrado ímpeto iconoclasta nos seus primeiros anos (Carvalho, 1990), a data oferece mais: marca o fato de forma laica, ao destacar o dia da posse, um dia político, diplomático e militar. Desvia o fato da coincidência com as festas pascais, que ocorre pelo acaso que geralmente é tomado como providência divina: o Brasil nasce, nessa vertente, de parto cesariano, e não naturalmente, nasce pela ação dos homens, de um ato político e jurídico, e não por força da natureza e / ou vontade divina. Voltando à metáfora do território, 03 de maio constitui uma fronteira política, enquanto o 22 de Abril constituiria uma espécie de fronteira natural, como a costa, as montanhas ou os rios. Além da comodidade de embarcar na tradição e evitar embates com fracas chances de sucesso, como havia ocorrido com o hino e a bandeira nacional, a opção pelo 3 de Maio marca os sujeitos da história: os homens (não qualquer homem, mas os grandes homens) e não a providência, e o Estado, com aqueles homens a seu serviço. Em 2000, o 22 de Abril aparece como data natural, livre de problemas: a passagem do 3 de Maio ao 22 de Abril ao longo do século XX é um assunto que merece um estudo a parte, embora possamos levantar a hipótese de que se trata de um resultado do crescimento e fortalecimento do discurso dos historiadores, alimentados pelo caráter testemunhal das fontes, sobretudo da Carta de Caminha e a decantação do seu uso pelo vulgo como certidão de nascimentodo Brasil, idéia que circulava mais restritamente entre as elites intelectuais, eposteriormente generalizou-se aos letrados com a progressiva expansão dos sistemas educacionais e do acesso cada vez mais amplo a eles por parte da população.

Controvérsia maior envolve a extensão desse território do tempo da nação. Enquanto o século XIX, através dos seus principais jornais ${ }^{4}$, fala em $I V$ Centenário do Descobrimento do Brasil, o século XX, através sobretudo da televisão, fala em "500 anos de Brasil", ou seja, subentende-se que no século XIX a constituição da nacionalidade não é datada no descobrimento, ao contrário do século de XX, que reivindica a idade de 500 anos (ao menos) para a coletividade que se comemora. Bem entendido: estamos nos debruçando não sobre os detalhamentos, as explicações, mas sobre os títulos de cada festa como suas marcas e seus símbolos, capazes de indicar seu sentido.

4 Em 1900, o principal jornal brasileiro é "0 Paiz"; o jornal "0 Estado de São Paulo", entretanto, fala em " 4 " Centenário do Brazil". 
A data estabelece sentidos. Consonando com a data de 3 de Maio, Dario Veloso, identifica o Descobrimento ao processo de iluminação do mundo e superação das trevas medievais promovido pelo Renascimento:

Quando a luz alva do século XV começou a illuminar os horizontes da Europa, esfuminhados no crepusculejamento das Edades medievas, nos torreões sombrios do feodalismo agonizante bruxoleavam lampadas de Alchimistas e o Mar Tenebrozo sentio que vigorosa dextra lhe amainava o dorso espumejante. Dos limbos das edades mortas surgiam espectros de civilizações idas, para a brilhante Renascença com que se encetaria o grandioso cyclo dos Tempos Modernos. (...) era o Brazil mais um florão que se engastava em a Corôa de Portugal. De posse da terra, o almirante destacou um baixel, sob o comando de Gaspar de Lemos, para que levasse ao Reino a fausiosa noticia; emquanto elle, almirante, singrava as agoas do Atlantico, em rumo do Levante, - para as Indias. Era assim descoberto o BRAZIL, a 3 de Maio de $1500{ }^{5}$

Em 2000, os sujeitos que afirmam os "500 anos do Brasil", dão uma resposta simples para a questão o que é a nação brasileira: é o grupo unificado de pessoas, instituições e território, que tem em 22 de abril de 1500 o seu ponto de partida. Mas essa definição através do marco temporal não é inocente nem necessária: ela ancora a coletividade nacional na origem portuguesa, ou ganha para ela a demarcação temporal da nação. Mas em 2000 os outros sujeitos da História não estão mais dispostos a aceitar tranquiilamente este padrão erigido no solo do tempo, como se havia aceitado a liderança de Capistrano de Abreu na estruturação dos significados do Descobrimento para a interpretação do Brasil que se seguiria. Capistrano vê a carta de Pero Vaz de Caminha como a certidão de nascimento da nova nação. Nesta data, por esta leitura, o Brasil entra na história, ou a história do Brasil é inaugurada triunfalmente. No que hoje é o território brasileiro, não haveria história até então, afinal os nativos não haviam desenvolvido a escrita, e na definição do século XIX, só há história quando há escrita, e quando há documento escrito que possa testemunhar o que passou. Isso não impede, claro, o aparecimento de antecedentes da história do Brasil. Mas onde buscá-los? Em Portugal, de onde emana a história.

\footnotetext{
5 VELOZO, Dario. Descobrimentos maritimos. O Brazil. In: PERNETTA, Emiliano (dir.). O Paraná no $4^{\circ}$ Centenário do Descobrimento do Brazil. Número especial de "Club Coritibano", Coritiba, 3 de Maio de 1900.
} 
Essa visão profundamente eurocêntrica estabelece uma posição de inferioridade para 0 indígena: não tem história, não tem tecnologia avançada, não tem civilização. Tudo é trazido pelo português. Qualquer um pode perceber a pesada carga de chamar os povos indígenas pré-cabralinos de pré-históricos. Sem a preocupação do politicamente correto que nos policia hoje, Capistrano de Abreu caracteriza o Brasil como herança de Portugal, e deixa clara a sua leitura da participação do indígena:

Sociologicamente, os descobridores do Brasil foram os Portuguezes.

Nelles inicia-se a nossa história, por elles se continua por séculos; a elles se devem principalmente os esforços que produziram uma nação moderna e civilizada em território antes povoado e percorrido por broncas tribus nomadas. ${ }^{6}$

Mas nos 500 anos, os índios também reivindicam um passado conforme os seus interesses, que permita sustentar suas reivindicações de terra, voz e poder dentro (ou apesar) do Estado Nacional. No debate promovido pela TV Cultura, de São Paulo, na noite do dia 22 de Abril de 2000, ao lado de nomes como Marilena Chauí e Bóris Fausto, o índio Ailton Krenak afirmou que os 500 anos eram um marco secundário, e que ele poderia, do referencial de sua cultura, falar em mil, dez mil, quinze mil anos. Marcos Terena afirmou também que "os quinhentos anos falados não correspondem ao relógio indígena", preferindo cobrar para o futuro o significado do reconhecimento dos índios, que ocorria naquele ano:

(...) a preocupação da gente é a seguinte: o que vai acontecer depois das 18 horas do dia 22 de Abril? Porque no 22 de Abril a Igreja Católica vai pedir perdão, vai ter um grupo de evangélicos que vai fazer orações, 0 Greca vai inaugurar um bando de coisas e os turistas, os festeiros, vão jogar um monte de latinha de Coca-cola lá, mas qual o compromisso que os índios vão ter de concreto do governo brasileiro, não só em relação ao resgate da história indígena, mas também em relação à perspectiva de futuro??

6 CAPISTRANO DE ABREU, João, O Descobrimento do Brasil. s.l.: Sociedade Capistrano de Abreu, 1929. O original é texto de concurso de cátedra do autor para o Colégio Pedro II, em 1883.

7 Marcos TERENA. Entrevista dos 500 anos. Revista Caros Amigos, ano IV, n. 37, abril 2000, p. 37. 
Nesta fala de Terena, percebe-se, ao lado de uma postura de cobrança e de reivindicação de um passado próprio e do respeito a ele, também uma determinada adesão ao Estado Nacional, no mínimo ao cobrar seus débitos junto às nações indígenas, cujos territórios e vidas foram subtraídos para a criação do Brasil. A voz do índio, ao fazer estas cobranças, escancara a incomemorabilidade dos 500 anos, especialmente ao cobrar, em vez de festa, as reparações pelo prejuízo histórico causado aos que aqui habitavam antes da chegada de Cabral. Trata-se de exigir, junto com a liberdade, autonomia e condições dignas dos indígenas de hoje, a liberdade, autonomia e dignidade de seu passado.

Esta polêmica não foi original, visto que em 1992, nos 500 anos da chegada de Colombo à América, a grande polêmica intercontinental sobre a festa ganhou espaço. 0 que seria uma grande comemoração do encontro de povos e culturas, tornou-se um debate sobre o significado do descobrimento da América, não apenas para os personagens daquela época, mas principalmente para os personagens atuais, habitantes da Europa e das Américas. Rediscutiuse o papel de Cristóvão Colombo: um grande herói da civilização ou um inaugurador de um genocídio estarrecedor de indígenas, e depois de negros? Este questionamento desaguáva no problema: fazer festa ou protestar? Talvez pelo histórico isolamento cultural entre o Brasil e os países de colonização hispânica, essa discussão envolveu pouco as pessoas por essas nossas paragens, seu significado pesou pouco no cotidiano de cada um de nós. Mas em 2000 não houve como fugir: meios de comunicação, empresas, governo, escolas, a questão dos 500 anos da chegada de Cabral, questão que é aparentada a dos 500 anos da chegada de Colombo, impôs-se. E apesar do congraçamento nacional planejado nos corredores oficiais, a discussão forçou a porta e adentrou o recinto, ao contrário do que se passou em 1900. Como em 1900, mas com um destaque maior para negros e índios, a presidência da República planejou a celebração de que, apesar de vários, nos fundimos e somos e seremos os mesmos:

Encontram-se em andamento três eventos componentes da "Chama do Conhecimento", atividade representada por fogo simbólico aceso no dia 26 de novembro na Serra da Capivara (PI), pela comunidade indígena, no dia $1^{\circ}$ de dezembro, pela comunidade negra de do Quilombo dos Calungas (G0), enquanto no dia 11 de dezembro, em Lisboa, foi acesa a Chama do Conhecimento Lusitano. 
As chamas representativas do conhecimento dos povos que originaram a nação brasileira encontram-se na cidade do Rio de Janeiro e, juntas, acenderam os fogos de boas-vindas ao ano 2000 naquela cidade; agora, fundidas numa só chama, percorrerão as diversas cidades do Brasil, iluminando as melhores ações na área de educação, saúde, voluntariado, até chegar à cidade de Porto Seguro (BA), no dia 22 de abril de 2000 , onde acenderão os fogos dos 500 Anos. $^{8}$

Índios e negros são convidados na medida em que vão à festa dizer que são os mesmos, e que se orgulham disso. Portugueses são chamados para uma espécie de benção paterna. Em 1900, apenas os portugueses são chamados, e são representados pelo embaixador general Cunha. A festa ocorre como o planejado, com missa campal, banquetes, recepções, inauguração de monumento, retretas. Não há interrupções ou protestos, a não ser o pano do monumento que insiste em não cair, obrigando um popular a galgar a estátua a Pedro Álvares Cabral, na Praça da Glória, no Rio de Janeiro, e descobrir o monumento ${ }^{9}$. Em 2000, diferentemente, "novos personagens surgem em cena".

Em ambas as festas, dimensão mais visível é a do Brasil português, marcada desde o início pela opção predominante, que marca a origem da coletividade no descobrimento lusitano. Fisicamente, o monumento dessa herança, dessa filiação, é a estátua de Cabral na Praça da Glória, inaugurada pelo presidente do Brasil e pelo representante do soberano português Carlos I, o general Francisco Maria da Cunha. 0 pavilhão provisório em madeira para abrigar as festas trazia, em seus ângulos, a costura de datas: "1500, 1822, 7 de Setembro, 1888, 13 de Maio, 1889, 15 de novembro".

Um outro monumento é a obra Porque me ufano do meu país, de Affonso Celso, também de 1900, dada a lume com o objetivo de ensinar o patriotismo, aos filhos do autor e aos filhos da Pátria todos ${ }^{10}$. Nele, e em tantos outros autores, negros e índios aparecem como tranqüilos alicerces e afluentes da obra do português. José do Patrocínio assim escreve, na data da festa:

8 Brasil, Presidente (1995-2002: F.H. Cardoso). Mensagem ao Congresso Nacional: abertura da 2a Sessão Legislativa Ordinária da $51^{\text {a }}$ Legislatura. Brasília: Presidência da República, Secretaria de Comunicações de Governo, 2000, p. 186.

9 A Cidade do Rio. Quinta-feira, 3 de Maio de 1900, p. 2.

${ }^{10}$ Celso, Affonso. Porque me ufano do meu país. 3 ed. Rio de Janeiro: Expressão e Cultura, 2001. 
A nossa alma nacional tem raízes de quatro seculos, que bebem o humus da fusão de todas as raças, que se unificaram n'um só sentimento, n'uma só fé, no mesmo patriotismo; ninguém nos poderá arrebatar uma parte do território; é preciso que nol-o arranquem todo, porque de um ou outro extremo d'elle, apesar da sua vastidão, todos nós nos sentimos tão irmãos agora como em 1640, optando pela tradição portuguesa. ${ }^{11}$

E nas vésperas, assim escreve o redator e proprietário da Cidade do Rio:

Nenhuma pompa eguala-se a que hontem se ostentou nas ruas atravessadas pelo Embaixador Portuguez. Eram o espirito e o coração do Brasil, no que tem de mais delicado e mais trabalhado pelas letras e pelas sciencias, pelas artes, o que formavam o triumpho.

0 que estava nos lábios era o que estava no pensamento, sem ressalvas, sem rebuço.

Era o tornar a ver o Pae que se apartou queixoso, mas benevolo desde 1822 e que nem offendido por uma ingratidão, em 1894, se mostrou menos gentil, menos cavalheiroroso, menos amigo. ${ }^{12}$

Com centro na capital da República, a festa terá como participantes, portanto, o governo brasileiro, os representantes da monarquia portuguesa e a população urbana do Rio de Janeiro, esta contando com a distinção dos militares e escolares em desfile, com as corporações profissionais e com o clero. Nada embaça a europeidade da festa, conduzida pela Associação do $4^{\circ}$ Centenário, presidida pelo Dr. Ramiz Galvão. 0 clima de festa é construído pela programação que antecede e que continua após a data cívica, pela decoração das ruas, vitrines e empresas em geral, pela venda de bilhetes da Loteria do Quarto Centenário, pela distribuição da tiragem especial de fósforos "Pedro Álvares Cabral". A comemoração não se restringe à data de 3 de Maio: espalha-se pelo cotidiano.

Em 2000, a festa é premeditada pela instalação dos relógios dos 500 anos nas principais cidades, pela Rede Globo de Televisão, que nos principais horários

\footnotetext{
${ }^{11}$ Patrocínio, José do. Quarto centenário. Cidade do Rio. Anno XII, n. 103, 3 de Maio de 1900, p. 1.

${ }^{12}$ Patrocínio, José do. Aperto de mão. Cidade do Rio. Anno XII, n. 100, 30 de Abril de 1900, p. 1.
} 
da sua programação diária também fazia saber quantos dias faltavam para "os 500 anos do Brasil".

A festa de 2000, então, é paradigmática dos tempos de hegemonia liberal em que ocorre: a nação nafesta do pretenso aniversário de seu surgimento écomemorada por uma empresa privada, que convida o Estado a participar da festa, de acordo com seus termos. Privatização da memória histórica. Não que o Estado não tenha se mexido: criou-se o comitê de empresários e governo para generalizar a marca e a idéia da comemoração, investiu-se em alguns atos simbólicos como a construção de uma réplica de caravela e a participação de um pavilhão do Brasil na Feira de Hannover. Mas foi completamente soterrado pela presença massiva das mensagens da Rede Globo no dia a dia da população. Destino diferente não poderia ter o fórum "Brasil: Outros 500, resistência indígena, negra e popular", organizado por entidades de defesa dos interesses indígenas, movimentos negros e outras organizaç̃oes como sindicatos, Movimento dos Trabalhadores Rurais Sem-Terra, etc.

Como já foi dito, nessa festa, apesar de tudo indicar o contrário, a voz dos excluídos da narrativa, os incomemoráveis, fez-se ouvir e destruiu a festa. 0 dia seguinte não foi dia de doce recordação do júbilo, mas de recolhimento dos cacos de uma leitura ingênua da nacionalidade, para jogá-la na lata de lixo da História (que infeliz ou felizmente fica fixada no teto, com a boca para baixo).

\section{0 fim da inocência}

Mais que memória, o ritual cívico, a exemplo do ritual católico, é revivência, é reacontecimento. Por isso, os símbolos e os gestos são imitados:

A narrativa relata acontecimentos históricos - mas acontecimentos históricos transfigurados pela mitificação que os transformou em substâncias inalteráveis e imutáveis. 0 conteúdo dos mitos é representado como não estando sujeito a qualquer espécie de mudança. 0 mito ensina que a história não é um jogo de forças contingentes. (CONNERTON, 1993, p. 51)

Em 1900, o 3 de Maio é iniciado na cidade do Rio de Janeiro com uma missa campal, diante de uma grande e tosca cruz feita com pau-brasil. É 
indisfarçado o desejo de praticar uma nova primeira missa, como a marcar no tempo pela repetição, o cristianismo e a condição européia da fundação. Menos católico, o Brasil em 2000 também realiza os rituais na praça pública de Porto Seguro, mas diferentemente de 1900 , a cidade é cercada por tropas da polícia militar do estado da Bahia, diante da ameaça de centenas de ônibus nos quais índios, negros e participantes de movimentos sociais de oposição às elites dirigiam-se para a cidade para arrancar um lugar na festa e fazer ouvir sua voz. Se em 1900 a festa tinha logrado ser quase privada, protegida até mesmo dos negros dos subúrbios por propagar-se apenas pelos jornais e pelos canais de comunicação das repartições públicas e dos estabelecimentos comerciais e industriais, enfim, pelos canais de comunicação de bem-nascidos, remediados e seus agregados, em 2000 a televisão escancara o anúncio para todo o Brasil: o contraponto de atingir a todos é que a festa perde o caráter quase privado que tinha no último ano do século XIX.

A tentativa de cercar a cidade para manter seu aspecto privado, ou seja, de preservar a festa para convidados, colaboradores, pessoas que sabiam que lugar ocupar para que o espetáculo ocorresse conforme planejado, acabou tendo um efeito simbólico sensacional na representação da nacionalidade. Uma cidade em que os bem-nascidos e seus agregados vivem uma fantasia de cordialidade, protegida com ferramentas de força e violência por herdeiros dos bandeirantes e capitães-do-mato, mantendo do lado de fora os sustentáculos da riqueza: herdeiros dos índios e dos negros da colonização, herdeiros sem herança do dado central da evolução histórica do Brasil, a concentração de renda, de terra, de poder político.

Ao forçar a entrada para usar a palavra e reivindicar que aquele momento não fosse de belas e vazias palavras, mas de compromisso com a mudança da tradição excludente, os novos personagens da festa deram motivo para a repressão policial: tropa de choque, cavalos, bombas, tiros, gás lacrimogêneo, sangue. Não conseguiram entrar, e a festa correu conforme o planejado. Mas a televisão, que dera hora e endereço da festa para os não - convidados (como dá preço e local de produtos que os pobres jamais poderão comprar), gerou uma lógica que não permitiu que a festa bem-sucedida fosse a única a aparecer. Tendo o confronto ocorrido a tarde, ficou sem cobertura pela Rede Globo até 0 início da noite: quem planejara por tantos meses uma festa sem jaça, poderia 
aguardar um pouco mais ou minimizar o confronto. Mas não há mais monopólio, e outras redes começam, já no final da tarde, a exibir as cenas dramáticas que ameaçam representar a nação melhor que as cenas da festa protegida em Porto Seguro. Para não dilapidar mais seu maior patrimônio, a credibilidade, a Rede Globo inicia seu jornal das 20 horas com as cenas da tragédia, e por mais que se esforce em concentrar a culpa em policiais malpreparados, em arruaceiros procurando confusão, em governo do Estado da Bahia, as cenas falam muito alto ao imaginário que vinha sendo alimentado, para que sejam ignoradas. Índios sendo agregidos violentamente na data em que se comemoraria o encontro pacífico, marcador de uma convivência cordial por tantos séculos, pedindo calma, implorando clemência aos policiais, tudo isso explode a festa, mata sem piedade o romantismo ingênuo e elitista de uma nação que, apesar do passado às vezes não tão desejável, congraça-se em nome de sua unidade e de seu futuro comum. As imagens mostram que não somos, nunca fomos, nunca seremos os mesmos, e para convivermos ainda precisamos reinventar um pacto de convivência, após saldar as dívidas do passado, mesmo que não as tenhamos feito.

0 correspondente da cruz de pau-brasil para missa em 1900 é uma réplica de caravela, que consome milhões do Ministério do Turismo, mas, por incompetência dos patrocinadores e construtores, mesmo com a acoplagem de um motor moderno, não logra navegar sem a humilhante ajuda de um barquinho rebocador, para vexame dos organizadores. Em melhores condições, a cruz de 1900 saiu-se com maior sucesso em sua humildade.

$\mathbb{E}$ assim fechou-se no Brasil a fase das festas cívicas que traziam e tinham aceitação de uma história unívoca, linear, inocente. O dilaceramento, a carne e os ossos da nação expostos, mostram que o que mais nos constitui é a violência e a injustiça, e menos a mistura das raças, a concórdia e a colaboração dos brasileiros. Essa incomemorabilidade destrói a festa, como se colocasse um cadáver na soleira da porta da casa que deveria abrigar uma festa de aniversário. Um imenso vazio fica no lugar da festa, e assim deixamos o século XX com este cadáver às costas: que História, que identidade, que cidadania para qual ensino de História, para quem e para onde? 


\section{Referências bibliográficas}

BERGMANN, Klaus. A história na reflexão didática. São Paulo. Revista Brasileira de História. v.9, n. 19, p. 29-42, set. 89/fev. 90.

BITTENCOURT, Circe. As "tradições nacionais" e o ritual das festas cívicas. In: PINSKY, Jaime. O ensino de História e a criação do fato. São Paulo: Contexto, 1988.

CARVALHO, José Murilo de. A formação das almas: o imaginário da República do Brasil. São Paulo: Companhia das Letras, 1990.

CHAUÍ, Marilena. Brasil: mito fundador e sociedade autoritária. São Paulo: Fundação Perseu Abramo, 2000.

CHESNEAUX, Jean. Devemos fazer tábula rasa do passado? - Sobre a história e os historiadores. São Paulo: Ática, 1995.

CONNERTON, Paul. Como as sociedades recordam. Oeiras: Celta, 1993.

DE DECCA, Edgar S. Memória e cidadania. In: São Paulo (cidade). Secretaria Municipal de Cultura. Departamento do Patrimônio Histórico. O direito à memória: patrimônio histórico e cidadania. São Paulo: DPH, 1992.

FURET, François. A oficina da história. Lisboa: Gradiva, s.d.

HAUPT, Heinz-Gerhard. 0 lento surgimento de uma história comparada. In: Boutier e Julia (orgs.) Passados recompostos. Campos e canteiros da História. Rio de Janeiro: Editora UFRJ; Editora FGV, 1998.

NADAI, Elza. O Ensino de História e a "pedagogia do cidadão". In: PINSKY, Jaime. O ensino de História e a criação do fato. São Paulo: Contexto, 1988.

o Ensino de História no Brasil: trajetória e perspectiva. Revista Brasileira de História, São Paulo, 13 (25/26), 143-162, set.92 / ago.93.

OZOUF, Mona. L'École de la France - Essais sur la Révolution, I'utopie et l'enseignement Paris: Gallimard, 1984.

R0BIC, Marie Claire. Sur les formes de l'Hexagone. Mappe Monde. Montpellier, v. 4, p. 18-23, out-dez 1989. 


\section{National parties: use and didatization of the historical knowledge in the citizen's pedagogies}

\section{ABSTRACT}

If the History taught is the "the citizen's central pedagogy", it is necessary to recognize that their pedagogic work does not happen just in the school atmosphere. The present research tried to identify the "occult curriculum" of the national parties of the Discovery of Brazil, in 1900 and in 2000, identifying the historical knowledge used and their relationships with the respective contexts. The rising of information was made through the analysis of written documents, above all of the press. It was verified that the themes of the national party were similar in every moment, although the treatment is totally different: the chronology of the history, the definition of the historical subjects and the subject of the commemoration, the significance of the monuments, among others.

Key-words: History teaching, school knowledge, curriculum, national parties 